\title{
The Membrane Protein Sortilin Can Be Targeted to Inhibit Pancreatic Cancer Cell Invasion
}

\author{
Fangfang Gao, ${ }^{{ }^{\dagger}}$ Nathan Griffin, ${ }^{{ }^{\dagger}}$ Sam Faulkner, ${ }^{* \dagger}$ Xiang Li,${ }^{* \dagger}$ Simon J. King, ${ }^{\dagger}$ Phillip Jobling, ${ }^{* \dagger}$ Jim W. Denham, \\ Chen Chen Jiang, ${ }^{\ddagger \dagger}$ and Hubert Hondermarck* \\ From the School of Biomedical Sciences and Pharmacy* and the School of Medicine and Public Health, ${ }^{\ddagger}$ Faculty of Health and Medicine, University of \\ Newcastle, Callaghan; and the Hunter Medical Research Institute, ${ }^{\dagger}$ University of Newcastle, New Lambton, New South Wales, Australia
}

\author{
Accepted for publication \\ May 26, 2020. \\ Address correspondence to \\ Hubert Hondermarck, Ph.D., \\ School of Biomedical Sciences \\ and Pharmacy, University of \\ Newcastle, Life Sciences Bldg. \\ (LS3-35), Callaghan, NSW \\ 2308, Australia. E-mail: hubert. \\ hondermarck@newcastle.edu.au.
}

\begin{abstract}
Pancreatic cancer has a dismal prognosis, and there is no targeted therapy against this malignancy. The neuronal membrane protein sortilin is emerging as a regulator of cancer cell development, but its expression and impact in pancreatic cancer are unknown. This study found that sortilin expression was higher in pancreatic cell lines versus normal pancreatic ductal epithelial cells, as shown by Western blot analysis and mass spectrometry. The increased sortilin level in pancreatic cancer cells was confirmed by immunohistochemistry in a series of 99 human pancreatic adenocarcinomas versus 48 normal pancreatic tissues $(P=0.0014)$. Sortilin inhibition by siRNA and the pharmacologic inhibitor AF38469 strongly reduced the adhesion and invasion of pancreatic cancer cells without affecting cell survival and viability. Sortilin inhibition also decreased the phosphorylation of the focal adhesion kinase in Tyr925. Together, these data show that sortilin contributes to pancreatic cancer invasion and could eventually be targeted in therapy. (Am J Pathol 2020, 190: 1931-1942; https://doi.org/10.1016) j.ajpath.2020.05.018)
\end{abstract}

Pancreatic ductal adenocarcinoma is one of the most aggressive malignancies, with $<9 \%$ patient survival after 5 years. ${ }^{1}$ Current therapeutic approaches include surgery, radiotherapy, and chemotherapy. Surgery is the most common treatment for early-stage pancreatic cancer, but it can be performed in $<20 \%$ of patients. ${ }^{2}$ The main chemotherapeutic drug used to treat pancreatic cancer, gemcitabine, has only a limited efficacy; to date, there are no targeted therapies for pancreatic cancer. ${ }^{3}$

Sortilin, also known as neurotensin receptor-3, is a member of the Vps10p-domain receptor family, which was originally identified in neuronal cells. ${ }^{4}$ Sortilin was named after an intracellular sorting protein in yeast and has progressively emerged as a key player in the regulation of neuronal viability and function, acting through the regulation of intracellular protein trafficking. ${ }^{5}$ It has also been shown to directly associate and regulate the activity of various receptors for neurotrophic factors and neuropeptides, ${ }^{6}$ cytokine receptors, ${ }^{7}$ tyrosine receptor kinases, ${ }^{8} \mathrm{G}$ protein-coupled receptors, and ion channels. ${ }^{9}$ In addition to its involvement in the nervous system, sortilin is involved in several non-neuronal tissues and pathologic processes. For instance, it is expressed in adipocytes ${ }^{10}$ and myotubes, ${ }^{11}$ where it acts as a modulator of insulin signaling that regulates glucose transport into the cells. In hepatocytes, sortilin facilitates the export of very-low-density lipoproteins and thereby increases low-density lipoprotein cholesterol levels in plasma through binding to apolipoprotein B100. ${ }^{12}$ Moreover, sortilin is involved in lipid homeostasis by suppressing intestinal cholesterol absorption, ${ }^{13,14}$ and it has also been studied in atherosclerosis ${ }^{15}$ and where the genetic deletion of sortilin reduces atherosclerotic plaque size. ${ }^{16}$

In cancers, there is increasing indication that sortilin participates in the deregulation of cancer cell viability. Sortilin is overexpressed in breast, ${ }^{17}$ lung, ${ }^{18}$ and thyroid ${ }^{19}$ cancers. In glioblastoma, sortilin can promote cancer cell invasion through GSK-3 $\beta / \beta$-catenin/twist-induced

Supported by the Maitland Cancer Appeal Committee grant G1700836 (H.H.) and a China Scholarship Council grant (F.G.).

C.C.J. and H.H. contributed equally to this work.

Disclosures: None declared. 
mesenchymal transition. ${ }^{20}$ In colorectal cancer, sortilin participates in cancer cell adhesion and metastasis by stimulating Akt and focal adhesion kinase (FAK)-Src signaling. ${ }^{21}$ Sortilin also promotes tumorigenesis of neuroendocrine tumors in the small intestine, lung, and thymus through FAK and Src. ${ }^{22}$ Together, these data point to a potential role for sortilin in tumor progression; to date, however, the expression and potential impact of sortilin in pancreatic cancer have not been reported.

The current study investigated the expression and function of sortilin in pancreatic cancer. Our results show that sortilin is increased in pancreatic cancers and contributes to pancreatic cancer cell invasion.

\section{Materials and Methods}

\section{Cell Culture and Reagents}

Pancreatic adenocarcinoma cell lines PANC-1, MIA PaCa2, PaCa-44, and BxPC-3 were obtained from ATCC (Manassas, VA). All cancer cell lines were maintained in Dulbecco's modified Eagle's medium (11960-044, Gibco; Thermo Fisher Scientific, Waltham, MA) with $10 \%$ (v/v) fetal bovine serum (JRH Biosciences, St. Louis, MO) and $1 \%$ (v/v) Gibco GlutaMAX Supplement (35050061; Thermo Fisher Scientific) in a humidified incubator at $37^{\circ} \mathrm{C}$ with $5 \%(\mathrm{v} / \mathrm{v})$ carbon dioxide. Normal human pancreatic ductal epithelial (HPDE) cells were obtained from ATCC (CRL-4023) and cultured in Keratinocyte SFM containing 5 $\mathrm{ng} / \mathrm{mL}$ and $50 \mu \mathrm{g} / \mathrm{mL}$ bovine pituitary extract (17005042; Thermo Fisher Scientific). Estradiol (E8875) and tamoxifen (T5648) were purchased from Sigma Aldrich (St. Louis, MO). AF38469 is a pharmacologic inhibitor against sortilin purchased from MCE MedChemExpress (HY-12802; Monmouth Junction, NJ). Dimethyl sulfoxide (DMSO) was purchased from Thermo Fisher Scientific (TS-20688). DMSO was used to dissolve reagents (estradiol, tamoxifen, and AF38469). The same v/v DMSO concentration was used as no treatment (NT) control.

\section{Mass Spectrometry}

Sample preparation for mass spectrometry was performed by using standard protocols previously described. ${ }^{23}$ Q-Exactive Plus High Resolution Quadrupole-Orbitrap (Thermo Fisher Scientific) tandem mass spectrometry was used for assays. All tryptic endogenous sortilin peptides at specific charge states (precursor ion $\mathrm{m} / \mathrm{z}$ ) were predicted and analyzed by using Skyline-daily software 64-bit, version 4.1.1. 18151 (MacCoss Lab, University of Washington, Seattle, WA).

\section{Transfection with siRNA}

Cells were transfected with $10 \mathrm{nmol} / \mathrm{L}$ of siRNA using lipofectamine RNAiMAX (13778150; Thermo Fisher Scientific) according to the manufacturer's recommendations.
Cells were seeded in 6-well plates an1d transfected 24 hours later with siRNA against sortilin (siSORT CUCUGCUGUUAACACCACC[dT][dT]; Sigma Aldrich), and a second siRNA against sortilin has been used (siSORT\# UUUACAACCUAUGCAAAUGG; Sigma Aldrich). A control siRNA sequence commercially available from Sigma (MISSION siRNA Universal Negative Control \#1) was used as siCTRL. The efficiency of sortilin knockdown was assessed by using Western blot analysis.

\section{Western Blot Analysis}

Western blot analyses were performed, as previously described, ${ }^{17}$ with anti-sortilin (1:500 dilution, ANT-009; Alomone Labs, Jerusalem, Israel) and mouse anti- $\beta$-actin (1:5000 dilution, A2228; Sigma Aldrich). Antibodies from Cell Signaling Technology (Danvers, MA) were also used in a dilution of 1:1000 for SRC proto-oncogene, non-receptor tyrosine kinase (Src) (2100), phospho-Src (Tyr416; 2101), FAK (1009), phospho-FAK (Tyr576/577; 3281), extracellular signal-regulated kinase 1/2 (Erk1/2; 9107), phospho-Erk1/2 (Thr202/Tyr204; 4370), AKT serine/threonine kinase 1 (Akt) (9272), phospho-Akt (Ser473) (9271), glycogen synthase kinase 3 beta (GSK-3ß) (9832), and phospho-GSK-3 $\beta$ (Ser9; 5558).

\section{Cell Viability Assay}

Cells were collected from 72 hours' post-transfection (siSORT or siCTRL) or 24 hours of treatment with 10 $\mu \mathrm{mol} / \mathrm{L}$ AF38469. Transfected cells or treated cells were seeded in a 96-well culture plate at $5 \times 10^{3}$ per well and subsequently incubated with CellTiter-Blue (G8081; Promega Corporation, Madison, WI) at $37^{\circ} \mathrm{C}$ for 4 hours; fluorescence was then recorded at 560/590 nm.

\section{Apoptosis Assay}

To assess cell apoptosis, $1 \times 10^{6}$ cells with sortilin-inhibited treatments were incubated with $100 \mu \mathrm{L}$ of Muse Annexin V and Dead Cell Reagent (MCH100105; Merck Millipore, Darmstadt, Germany) for 20 minutes at room temperature per the manufacturer's instructions. Analysis was performed by using the Becton Dickinson FACScan flow cytometer (Franklin Lakes, NJ), and the statistics obtained revealed the percentage of the cells represented by alive, apoptotic, and dead populations.

\section{Adhesion Assay}

Pancreatic adenocarcinoma cells were transfected with siSORT or siCTRL as indicated above (Cell Viability Assay). Cancer cells were treated with the sortilin inhibitor AF38469 as indicated above. Cells were detached after the treatments by using trypsin free TrypLE Express solution (12604-013; Thermo Fisher Scientific) and seeded at a concentration of 
A

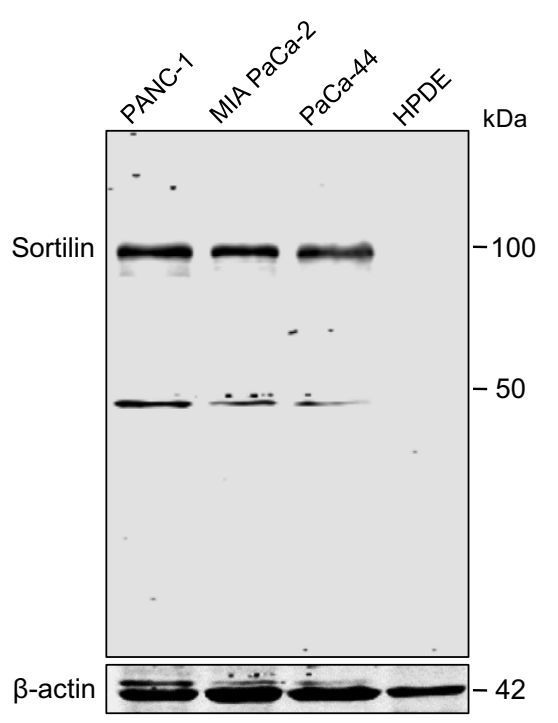

B R.DPIYFTGLASEPGAR.S [564, 578] (Endogenous) $\mathrm{m} / \mathrm{z}=531.9351+++$
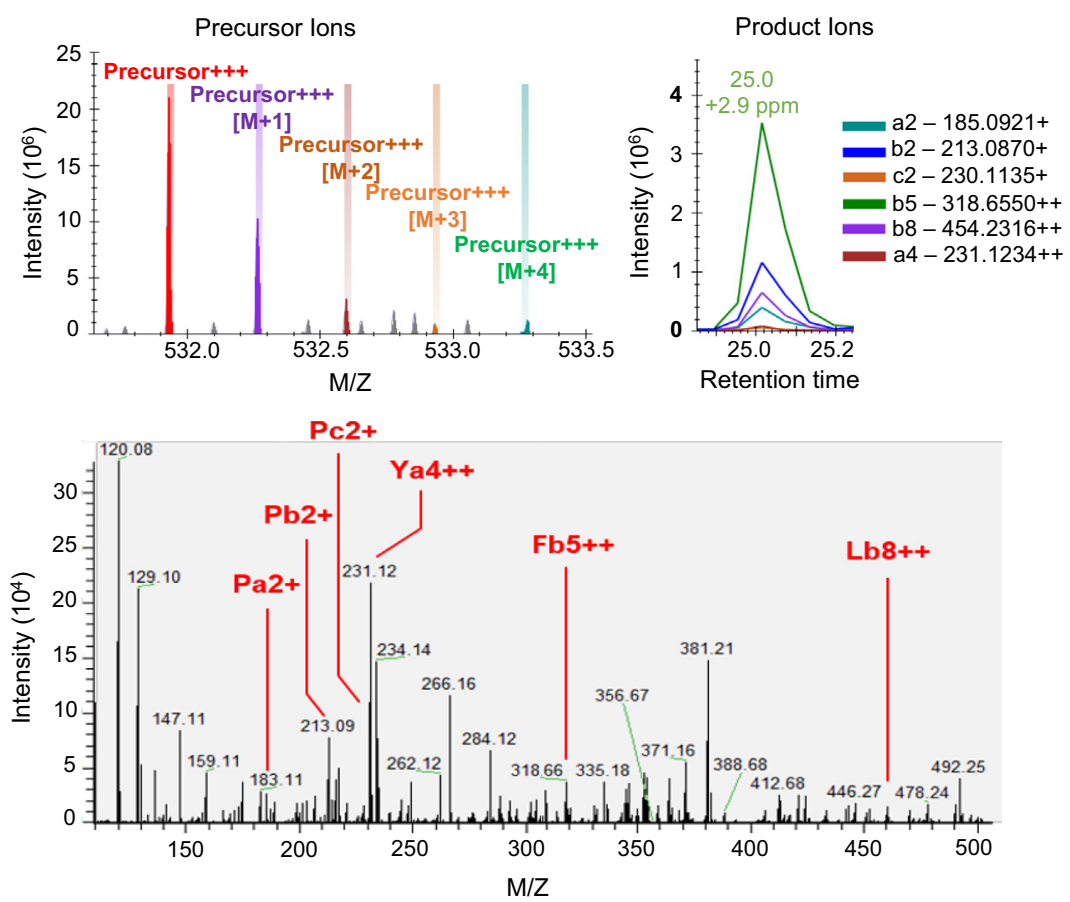

Figure 1 Expression of sortilin in pancreatic cancer cell lines. A: Western blot analysis for detection of sortilin was performed in cancer cell lines (PANC-1, MIA PaCa-2, and PaCa-44) and human pancreatic ductal epithelial (HPDE) cells. A band at $100 \mathrm{kDa}$, the expected molecular weight of sortilin, is observed in PANC-1, MIA PaCa-2, and PaCa-44. An additional minor band at $\sim 50 \mathrm{kDa}$ is detected. Neither of these bands are detected in HPDE cells. $\beta$-actin was used as loading control. B: Mass spectrometry detection of sortilin (PANC-1 is shown as an example). Mass spectrometry accurately detects the sortilin peptide R.DPIYFTGLASEPGAR.S with a major precursor ion mass of $531.9351 \mathrm{M} / \mathrm{Z}$ and charge state of +++ . A total of six high-quality product ions for this precursor ion are detected (each color peak represents one product ion) and validated in tandem mass spectrometry spectra.

$10^{5}$ cells/mL in 12-well Corning cell culture plates (Corning, NY). After 2, 4, and 6 hours, adherent cells were counted under a phase contrast microscope.

\section{Migration Assay}

Pancreatic adenocarcinoma cells were seeded in 6-well plates $\left(5 \times 10^{5}\right.$ cells per well), and after 24 hours, the cell monolayer was scratched with a $200 \mu \mathrm{L}$ pipette tip, gently rinsed three times with phosphate-buffered saline, and replaced with media containing $0.1 \%(\mathrm{v} / \mathrm{v})$ fetal bovine serum. Cells were transfected with siSORT or siCTRL as transfection control. Cells were treated with sortilin inhibitor AF38469. After 6, 12, and 24 hours, the gap area was monitored by taking images of three random areas using a phase contrast microscope (Zeiss, Jena, Germany). The reduced gap areas were measured between 0 and 24 hours by using ImageJ software version $1.0(\mathrm{NIH}$, Bethesda, MD; https://imagej.nih.gov/ij), and the percentage of reduction areas was calculated relative to control as $100 \%$.

\section{Invasion Assay}

Pancreatic adenocarcinoma cells posttransfected with siRNA or posttreated with AF38469 were seeded in 24-well plates in triplicate by using a QCM ECMatrix Cell Invasion Assay kit (ECM550; Merck Millipore). After 48 hours' incubation at $37^{\circ} \mathrm{C}$, cells were detached from the bottom side of the inserts and dyed, then read with the fluorescence plate reader (BMG Lab-tech, Durham, NC) using a 480/520 $\mathrm{nm}$ filter set. In addition, cells invaded on the bottom side were fixed in $4 \%$ formaldehyde and stained with $0.01 \%$ crystal violet (Sigma Aldrich) for microscopic observation.

\section{Pancreatic Tissue Samples and Immunohistochemistry}

High-density tumor microarrays (TMAs) were obtained from US Biomax Inc. (Rockville, MD). The TMAs used (HPan-Ade170Sur-01) included a total of 99 pancreatic adenocarcinoma and 48 normal adjacent pancreatic tissues. The diameter of each core on the TMA was $1.5 \mathrm{~mm}$, and the thickness was $4 \mu \mathrm{m}$. Immunohistochemistry analysis of TMAs was performed as previously described. ${ }^{24}$ Negative controls, using a rabbit DA1E monoclonal antibody IgG XP isotype control antibody (3900; Cell Signaling Technology), are shown in Supplemental Figure S1. Hematoxylin and eosin staining of both pancreatic cancer and normal tissues are also presented (Supplemental Figure S1). The following clinicopathologic information was available: patient sex and age, histologic type, grade, stage, lymph node status, and patient survival. US Biomax Inc. quality controls are described as follows. Each single tissue spot on every array slide was individually examined by pathologists according to World Health Organization published standardizations of 


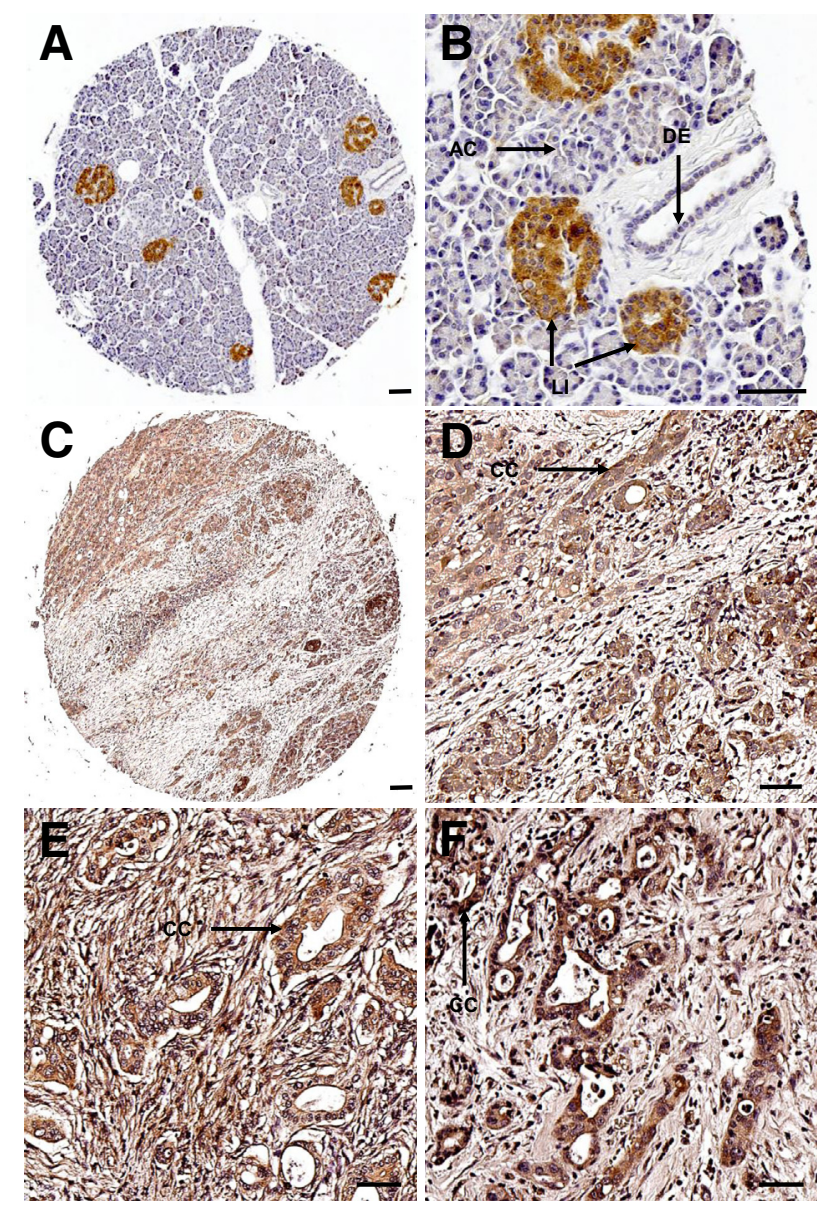

Figure 2 Immunohistologic detection of sortilin in clinical samples of pancreatic cancer. Immunohistochemical detection of sortilin was performed on a cohort of pancreatic cancers and normal adjacent tissues. A and B: Representative images of sortilin immunolabeling are shown. Although sortilin staining is not detected in normal pancreatic acinar cells $(A C)$ and ductal epithelial $(D E)$ cells, sortilin expression is high in Langerhans islets (LI) (A, entire core; $\mathbf{B}$, higher magnification). C and $\mathbf{D}$ : In pancreatic cancer, sortilin expression is observed in cancer cells (CC) but is weak in the stroma. $\mathbf{E}$ and $\mathbf{F}$ : Higher magnifications obtained for pancreatic ductal adenocarcinoma cells are positive for sortilin. Arrows indicate different cells in normal and cancer tissues. Scale bars $=50 \mu \mathrm{m}(\mathbf{A}-\mathbf{F})$.

diagnosis, classification, and pathologic grade. ${ }^{25}$ For each specimen collected, informed consent was obtained from both hospital and individual. Discrete legal consent was obtained, and the rights to hold research uses for any purpose or further commercialized uses were waived. In addition, the study was approved by the Human Research Ethic Committee of the University of Newcastle (H-2012-0063), and all experiments were performed in accordance with relevant guidelines and regulations.

\section{Digital Quantification of Immunohistochemistry Staining Intensities}

Quantification of staining intensities was performed as previously described ${ }^{18}$ by using the Aperio AT2 scanner
(Leica Biosystems, Mount Waverley, VIC, Australia) and the Halo version 2.0 image analysis platform (Indica Labs, Albuquerque, NM) under the supervision of a pathologist (S.J.K.). Pixel intensity values were used to determine the h-scores for each core (index calculated as the sum of $3 \times$ percentage of pixels with strong staining $+2 \times$ percentage of pixels with intermediate staining $+1 \times$ percentage of pixels with weak staining). Staining intensities were categorized as low (h-score $\leq 50)$ and high (h-score $>50$ ). To assess the association of clinical characteristics and sortilin intensity, simple linear quantile regression on the median was conducted for each of the independent variables and outcomes. Multivariable quantile regressions were conducted on the outcome sortilin. All of the regressions included only those observations that had no missing data for any of the variables involved. Statistical analyses were programed by using SAS version 9.4 (SAS Institute, Inc., Cary, NC). Each core of the TMAs was investigated, and the data were then submitted to statistical analysis (supported by Hunter Medical Research Institute, Clinical Research Design, IT, and Statistical Support unit, New Lambton, NSW, Australia).

\section{The Cancer Genome Atlas and R2 Database Mining}

The data of sortilin protein expression in pancreatic cancer were analyzed by using The Cancer Genome Atlas (TCGA) database. ${ }^{26}$ The correlation of gene expression with SORTI in pancreatic cancer was analyzed with the R2 Genomics Analysis and Visualization Platform (http://r2.amc.nl, last accessed May 27, 2020).

\section{Statistical Analysis}

Associations between clinicopathologic factors with sortilin were analyzed. Sortilin levels (h-scores) were regressed on clinical, demographic, and disease factors in separate univariable normal linear regressions. Participant characteristics stratified by using the h-score indicator $(\leq 50$ vs $>50)$ were displayed. The $\chi^{2} P$ values were used for categorical variables ( $\chi^{2}$ test of association) and analysis of variance $P$ values for continuous variables (test for equality of means). Multivariable quantile regression model was conducted on the outcome h-score of sortilin. The independent variables with $P<0.5$ in the simple quantile regressions were included in the multivariable regressions for that same outcome. Parameter estimates with $95 \%$ CIs computed by using the resampling method are provided. $P$ values given are from the null hypothesis that all of the parameters associated with that variable are zero. The association between survival time and $\mathrm{h}$-score was investigated by using Cox proportional hazards modeling. Statistical analyses were programed by using SAS version 9.4.

For cell viability, apoptosis, adhesion, migration and invasion assays, each condition was performed in triplicate, and statistical analysis was conducted by using Prism 
Table 1 Association between Sortilin Expression and Clinicopathologic Parameters in Pancreatic Cancer

\begin{tabular}{|c|c|c|c|}
\hline \multirow[b]{3}{*}{ Parameter } & \multicolumn{2}{|l|}{ Sortilin intensity } & \multirow[b]{3}{*}{$P$ value } \\
\hline & \multirow{2}{*}{$\begin{array}{l}\text { Low h-score } \leq 50 \\
\text { h-score } \leq 50\end{array}$} & \multirow{2}{*}{$\frac{\text { High h-score }>50}{\text { h-score }>50}$} & \\
\hline & & & \\
\hline Normal $(n=48)$ & $37(77)$ & $11(23)$ & \\
\hline Cancer $(n=99)$ & $49(49)$ & $50(51)$ & \\
\hline Male $(n=63)$ & $41(65)$ & $22(35)$ & \\
\hline Female $(n=36)$ & $8(22)$ & $28(78)$ & \\
\hline Age, years & & & 1.0000 \\
\hline$\leq 50(n=16)$ & $8(50)$ & $8(50)$ & \\
\hline$>50(n=82)$ & $41(50)$ & $41(50)$ & \\
\hline Grade & & & 0.3555 \\
\hline $\mathrm{T} 1+\mathrm{T} 2(n=78)$ & $39(50)$ & $39(50)$ & \\
\hline $\mathrm{T} 3+\mathrm{T} 4(n=20)$ & $10(50)$ & $10(50)$ & \\
\hline Lymph node status & & & 0.9357 \\
\hline Negative $(n=50)$ & $24(48)$ & $26(52)$ & \\
\hline Positive $(n=43)$ & $21(49)$ & $22(51)$ & \\
\hline Stage & & & 0.9340 \\
\hline $0+\mathrm{I}(n=40)$ & $20(50)$ & $20(50)$ & \\
\hline $\mathrm{II}+\mathrm{IV}(n=59)$ & $29(49)$ & $30(51)$ & \\
\hline
\end{tabular}

Data are expressed as $n$ (\%) unless otherwise indicated. Immunohistochemical staining in each tissue sample was digitally quantified and categorized as low staining ( $h$-score $\leq 50)$, or high staining ( $h$-score $>50$ ). Because some cases occasionally missed clinicopathologic parameters, the total number of patients varies in each parameter. The $\chi^{2}$ test was used to test statistical association.

${ }^{*} P<0.05$.

software version 8.0 (GraphPad Software, La Jolla, CA). The results of cell viability, migration, and invasion assays were compared by using a $t$-test, and cell adhesion over time was compared by using repeated measure two-way analysis of variance.

\section{Results}

\section{Sortilin Is Overexpressed in Pancreatic Cancer Cells}

Sortilin expression was initially analyzed by using Western blot analysis in pancreatic cancer cell lines (PANC-1, MIA $\mathrm{PaCa}-2$, and PaCa-44), as well as normal HPDE cells. In all cancer cell lines, a major immunoreactive band at $\sim 100$ $\mathrm{kDa}$, the expected molecular weight of sortilin, was observed; a minor band at $50 \mathrm{kDa}$ was also detected. This additional band has already been reported in the literature ${ }^{17}$ and may represent a degraded form of sortilin that warrants further characterization. Interestingly, no sortilin band could be found in the HPDE cells, indicating an increased protein expression of sortilin in the pancreatic cancer cell lines (Figure 1A). To further confirm the presence of sortilin in all cancer cell lines, mass spectrometry analysis was used. A total of 13 tryptic peptides of sortilin were detected in the pancreatic cancer cells by using mass spectrometry.
Two peptides (R.DPIYFTGLASEPGAR.S and R.FLFASVMADK.D) (Supplemental Table S1) were specific for sortilin. As an illustration, for peptide R.DPIYFTGLASEPGAR.S, five naturally occurring isotopic precursor ions were accurately detected, and a major precursor ion was detected with a mass of $531.9351 \mathrm{~m} / \mathrm{z}$ (Figure 1B). A total of six high-quality product ions (indicated by different colored peaks) were fragmented from the above precursor ions and detected with high mass accuracy (Figure 1B). In contrast, no sortilin peptides were detected in HPDE cells, confirming that sortilin is not expressed in normal epithelial pancreatic cells.

\section{Sortilin Expression Is Increased in Human Pancreatic Cancer Tissues}

To further investigate sortilin protein expression in pancreatic ductal adenocarcinomas and normal pancreatic tissues, immunohistochemistry was performed by using tissue microarrays. Digital quantification of sortilin, defined according to the h-score, was performed. To analyze the potential association between sortilin staining intensity and clinicopathologic parameters, $\mathrm{h}$-scores were categorized in either low (h-score $\leq 50$ ) or high ( $\mathrm{h}$-score $>50$ ) expression groups. In normal pancreatic tissues, sortilin was strongly expressed in Langerhans islets (Figure 2, A and B). 
Although sortilin was found in normal epithelial cells, the percentage of cases with high sortilin expression in epithelial cells was higher in cancer samples than in normal samples (51\% vs $23 \%$, respectively; $P=0.0014)$ (Table 1$)$. In pancreatic cancer, the expression of sortilin was mainly localized in cancer cells, as well as in some fibroblasts, a major type of cell in the stroma, which were also clearly positive for sortilin (Figure 2, C-F). Higher sortilin expression levels were observed in a large proportion of pancreatic ductal adenocarcinoma cells (Figure 2, C-F). Sortilin was expressed in the cytoplasm of cancer cells (Figure 2, C-F). Digital quantification indicated an increase in sortilin expression in cancer cells compared with epithelial cells in the normal pancreas $(P=0.0014)$ (Table 1). Sortilin expression (h-score $>50$ ) was found in $50 \%$ of pancreatic cancer tissues, and high sortilin expression (h-score $>70$ ) was found in $21 \%$ of pancreatic cancer cases. Together, these data show that sortilin protein expression is increased in pancreatic ductal adenocarcinoma.

\section{Sortilin Expression in Pancreatic Cancer Is Higher in Female Cases}

Comparison of sortilin expression with clinicopathologic parameters revealed a significant association between sortilin expression and sex $(P<0.0001)$ (Table 1), and multivariable quantile regression confirmed this association $(P=0.0468)$ (Supplemental Table S2) with more sortilin expression in female cases compared with male cases. However, when female cases were analyzed separately, no statistically significant associations were observed with other clinicopathologic parameters (Supplemental Table S3). The mean h-score in female patients was 64 compared with 49 in male patients. High sortilin expression was detected in $77 \%$ of female cancers versus $34 \%$ of male cancers (Figure 3A). In addition, The Cancer Genome Atlas database $^{26}$ for tumor pancreatic adenocarcinoma (TCGA178-rsem-tcgars, $n=178$; included 98 male and 80 female cases) was searched. The correlation analysis showed that there was a positive association between SORTI (sortilin gene) and ESRl (estrogen receptor gene) in pancreatic ductal adenocarcinoma $(R=0.207, P<0.001)$ (Figure 3B). In Western blot analysis, the antiestrogenic drug tamoxifen was found to reduce sortilin expression in BxPC-3 and PaCa-44 cells (Figure 3C). The BxPC-3 cell line was tested because it was originally derived from a female patient with pancreatic cancer, whereas the other three cell lines were derived from male patients. These results suggest that estrogen signaling may up-regulate sortilin expression. With regard to the other clinicopathologic parameters, no significant association was detected between sortilin expression and patient age, tumor size, stage, or lymph node invasion (Table 1). However, although no significant association was observed between sortilin expression and grade in univariable analysis (Table 1), a
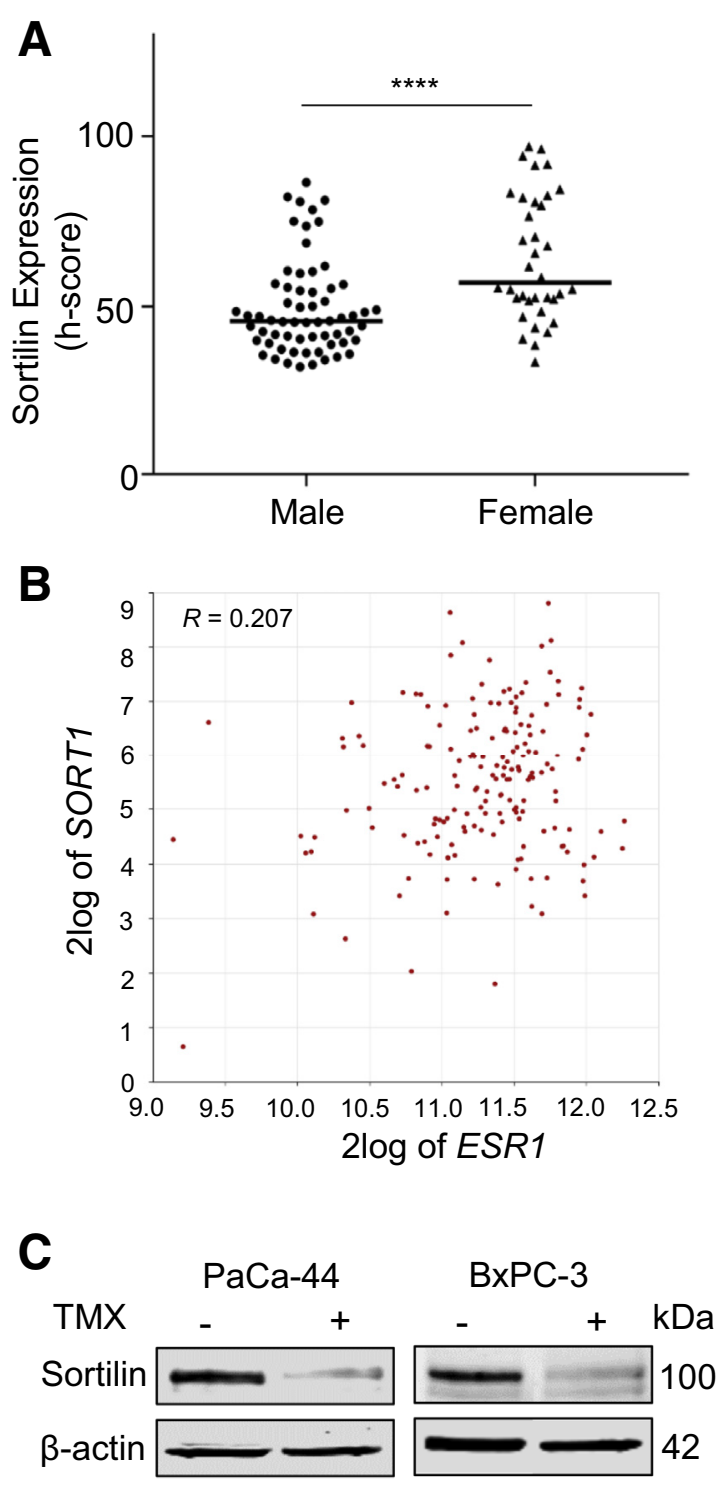

Figure 3 High sortilin expression in pancreatic cancer tissues from female patients. A: Sortilin staining was quantified by using the Halo image analysis platform, and h-scores were calculated. Sortilin staining intensities are higher for female cases (median h-score: 56.95) than male cases (median h-score: 45.64). Data are expressed as medians (horizontal lines indicate median values, and dots indicate each case). B: The correlation analysis of SORT1 and ESR1. The R2: Genomics Analysis and Visualization Platform was used to analyze the correlation between SORT1 and ESR1 $(P<0.001)$. The $y$ axis indicates $2 \log$ of SORT1, and the $x$ axis indicates 2log of ESR1. C: Western blot analysis was used to investigate sortilin expression in PaCa-44 and BxPC-3 cells after 24 hours of treatment by tamoxifen (TMX $20 \mu \mathrm{mol} / \mathrm{L}$ ). Sortilin expression decreases under treatment by tamoxifen. ${ }^{* * *} P<0.0001$.

significant association was found in multivariable analysis $(P=0.0467)$, with less sortilin expression in high-grade tumors (Supplemental Table S2). It is not unusual for multivariate analysis to yield results slightly different from those of univariate analysis, as the relative weighting of multiple variables is taken into account; however, this 

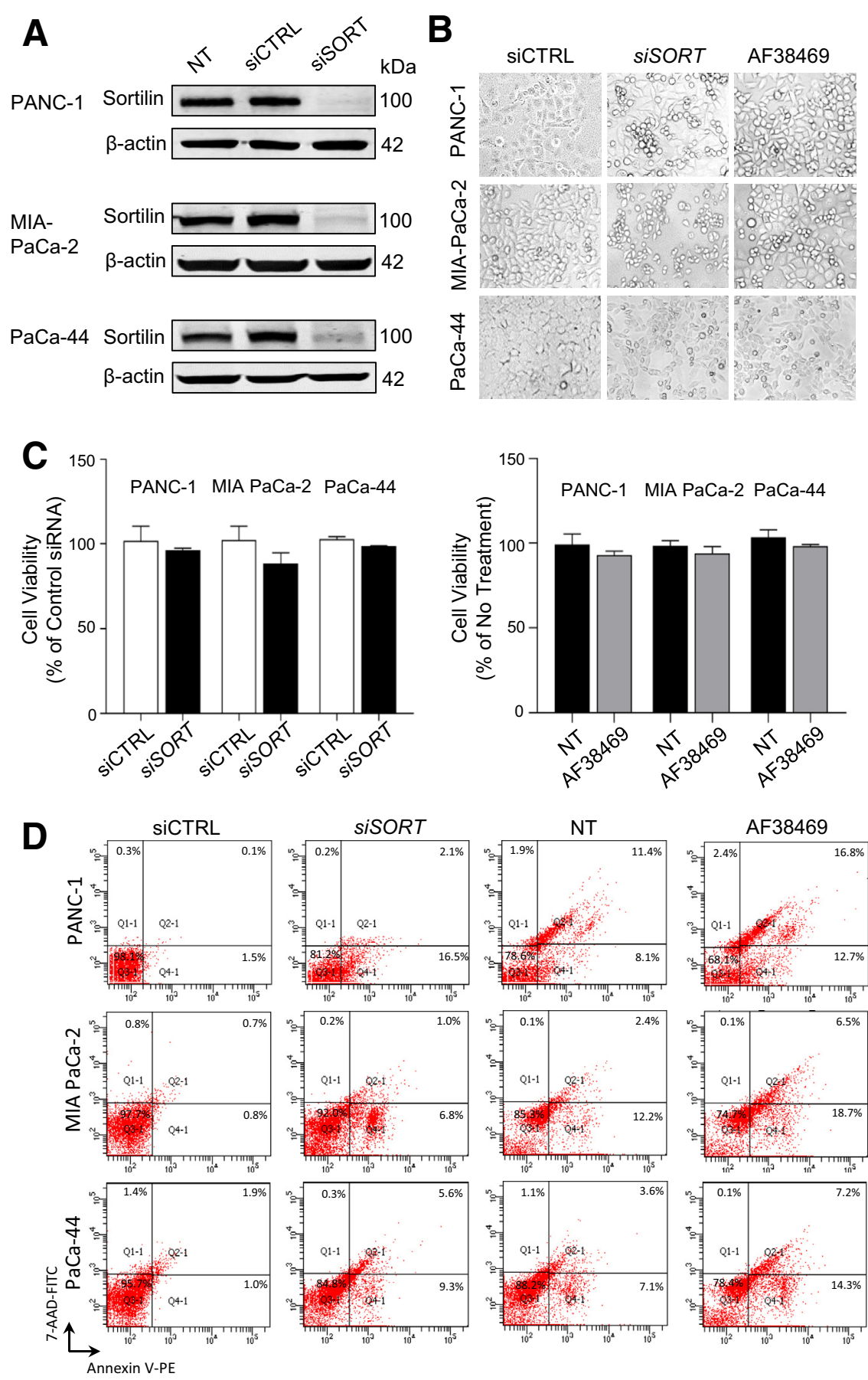

Figure 4 Impact of sortilin inhibition on pancreatic cancer cell line viability and apoptosis. siRNA against sortilin (siSORT) and the AF38469 sortilin pharmacologic inhibitor have no effects on the viability and survival of pancreatic cancer cells. A: siSORT and universal negative control siRNA (siCTRL) were transfected in PANC-1, MIA PaCa-2, and PaCa-44 pancreatic cancer cell lines. The impact on protein level of sortilin was measured by using Western blot analysis 72 hours after transfection. Nontransfected cells were also analyzed. B: Microscopic observations of pancreatic cancer cells posttransfected with siRNA (siCTRL) or siSORT or posttreated with AF38469 are shown. A large population of cancer cells are detached and have morphologic changes compared with the control. C: The viability of pancreatic cancer cells is studied. Left panel: PANC-1, MIA $\mathrm{PaCa}-2$, and $\mathrm{PaCa}-44$ cell lines were transfected with siSORT versus SiCTRL separately. The histograms represent relative mean percentage of alive cells. There is no significant difference between sortilin-inhibited and the siCTRL. Right panel: The viability of pancreatic cancer cell lines treated with AF38469 is measured. The histograms represent the relative mean percentage of alive cells. The changes between AF38469-treated and no treatment are analyzed as shown, with no significance. D: The impact of cell apoptosis is detected by using dual labels of Annexin $V$ and 7-AAD and analyzed via flow cytometry. Representative dot plots display that 03-1, 04-1, Q2-1, and 01-1, respectively, indicate the populations of the alive, early apoptotic, late apoptotic, and dead cells. The percentage of each cell population is calculated and marked at the upper-right corner. The percentages of dead cells in the sortilininhibited groups are low, with no statistical significance. Error bars represent SD. Original magnification, $\times 100$ (B). FITC, fluorescein isothiocyanate; NT, no treatment. discrepancy shows that further studies involving a larger number of samples are warranted to clarify a potential association between sortilin expression and grade.

\section{Sortilin Is Not Involved in Pancreatic Cancer Cell Viability and Apoptosis}

To investigate the functional impact of sortilin in pancreatic cancer cells, siRNA against sortilin (siSORT) and a pharmacologic inhibitor of sortilin (AF38469) were used.
Western blot analysis was used to assess the efficacy of siSORT at 72 hours after transfection. In PANC-1, MIA $\mathrm{PaCa}-2$, and $\mathrm{PaCa}-44$ cell lines, the down-regulation of sortilin was complete at 72 hours (Figure 4A). Microscopic observation of the posttreatments showed a higher proportion of round cells in siSORT and AF38469 than the corresponding controls (Figure 4B). Cell viability assays showed no significant changes between siSORT and siCTRL treated cells (Figure 4C). The sortilin pharmacologic inhibitor AF38469 was also used, and NT was set as 
negative control. The effects on cell viability and apoptosis were measured. There was no significant difference in cell numbers in AF38469-treated compared with NT in any of the three cancer cell lines (Figure $4 \mathrm{C}$ ). These results indicate that sortilin is not involved in the control of pancreatic cancer cell viability.

The impact of sortilin targeting on pancreatic cancer cell survival and apoptosis was next detected. The proportion of dead cells was recorded as $0.2 \%, 0.2 \%$, and $0.3 \%$ in sortilinsiRNA targeted samples in PANC-1, MIA PaCa-2, and $\mathrm{PaCa}-44$ cells, respectively. When pancreatic cancer cells were treated with AF38469, the proportion of dead cells was $2.4 \%, 0.1 \%$, and $0.1 \%$ in PANC-1, MIA PaCa-2, and PaCa-
44 cells (Figure 4D). The proportion of early apoptosis (Q4-1) was increased in the siSORT and AF38469 groups compared with their corresponding control groups. This indicated the decrease tendency of cell viability (Figure 4C). The proportions of alive cells (Q3-1) were $16.9 \%, 5.7 \%$, and $10.9 \%$ less in siSORT than in siCTRL in PANC-1, MIA $\mathrm{PaCa} 2$, and $\mathrm{PaCa}-44$, whereas there was $10.5 \%, 10.6 \%$, and 9.8\% fewer alive cells in PANC-1, MIA PaCa2, and PaCa44 in the presence of AF38469 compared with NT. This could explain the decrease of cell viability in sortilininhibited groups compared with their corresponding controls (Figure 4D). Forward scatter versus side scatter plots displayed no differences between siCTRL versus siSORT or
A
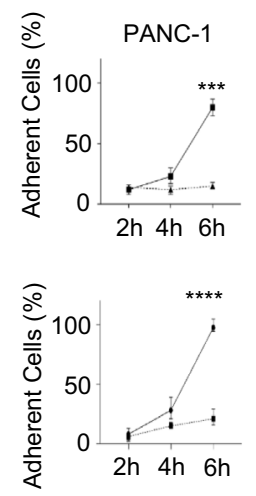

B
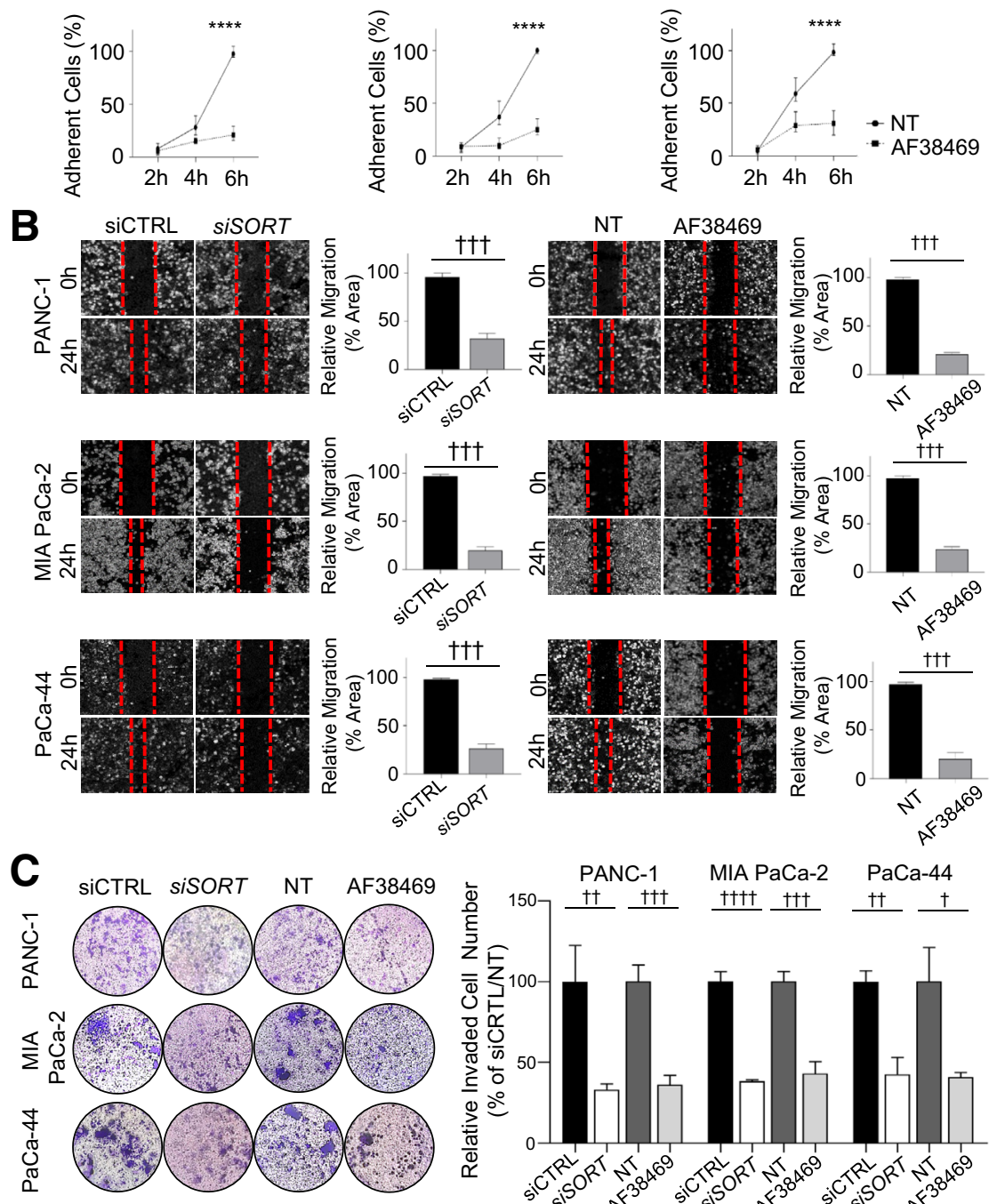

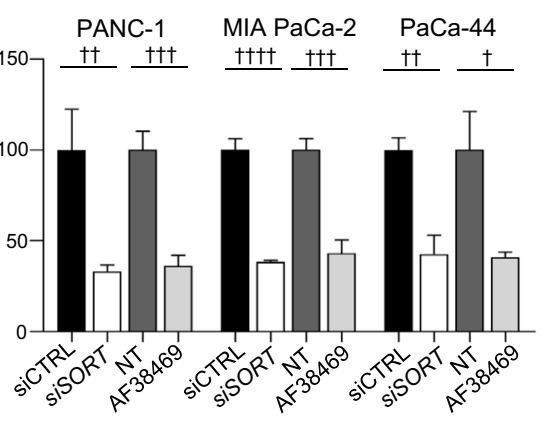

Figure 5 Impact of sortilin on adhesion, migration, and invasion of pancreatic cancer cell lines. siRNA against sortilin (siSORT) and the AF38469 sortilin pharmacologic inhibitor decrease the adhesion, migration, and invasion of pancreatic cancer cells. A: Impact of sortilin-inhibition on pancreatic cancer cell adhesion. Top row: Pancreatic cancer cells were transfected with SIRNA (siSORT or SiCTRL) and were seeded in culture dishes. Numbers of attached cells was counted at the indicated times $(2,4$, and 6 hours) after seeding. Results are expressed as percentage of adherent cells. Bottom row: Impact of sortilin inhibitor (AF38469) treatment on pancreatic cancer cell adhesion. Results are expressed as percentage of adherent cells. B: Scratching assay was performed. Pancreatic cancer cells (PANC- 1 , $\mathrm{PaCa}-2$, and $\mathrm{PaCa}-44)$ were transfected with siSORT or siCTRL. Left column: The gaps of 0 and 24 hours were recorded, and relative migration areas were analyzed as shown in the histograms. There is a significant decrease in siSORTtransfected cells. Right column: Scratching of the cell layer was performed with inhibitor (AF38469) treatment, and reductions in gap areas were measured after 24 hours. The percentage of cell migrating areas is represented in black and light gray columns individually as no treatment (NT) versus AF38469. A significant decrease is shown in AF38469-treated cells. The dashed red lines indicate scratch boundaries. C: Impact of sortilin-targeted inhibition on cell invasion. Left panel: The entire inserts (bottom side) with invading cells was observed after crystal violet staining. It reveals a decreased invasion in sortilin-inhibited samples with siRNA or AF38469. Right panel: Invaded cell numbers are shown in the histogram representing a decrease of sortilinreduced in invasion PANC-1, MIA PaCa-2, and $\mathrm{PaCa}-44$ cells. Error bars represent SD. $* * * P<0.001, * * * * P<0.0001$ siCTRL versus 2 hours, ${ }^{\dagger} P<0.05,{ }^{\dagger \dagger} P<0.01,{ }^{\dagger \dagger} P<0.001$, ††† $P<0.0001$. 
in NT versus AF38469 treatments in PANC-1, MIA PaCa2, and PaCa-44 cell lines (Supplemental Figure S2). Overall, these data show that sortilin inhibition does not significantly affect pancreatic cancer cell survival.

\section{Sortilin Is Necessary for Pancreatic Cancer Cell Adhesion, Migration, and Invasion}

The impact of sortilin inhibition on the adhesion of pancreatic cancer cell lines was then investigated. Cell adhesion was tested in the presence of SiSORT versus siCTRL and AF38469 versus NT. SiSORT induced a $68 \%$ inhibition of cell adhesion in PANC-1 $(P=0.0008), 78 \%$ in MIA PaCa-2 $(P<0.0001)$, and $71 \%$ in $\mathrm{PaCa}-44$ $(P=0.0003)$ (Figure 5A). Also, the impact on cell adhesion was measured in the presence of AF38469, which produced a $73 \%, 74 \%$, and $82 \%$ reduction of adhesion compared with NT in PANC-1, MIA PaCa-2, and PaCa-44 cells, respectively $(P<0.0001)$ (Figure 5A). It is likely that the reported change in cell shape induced by siSORT or AF38469 (Figure 4) reflects the decreased cell attachment induced by sortilin targeting. Together, these data show that sortilin targeting results in a decreased attachment of pancreatic cancer cell lines.

Wound healing assays were next performed to investigate the impact of sortilin on cell migration. Scratched areas were recorded 24 hours' postinhibition of sortilin by siSORT or AF38469. Changes in the scratched surface areas were measured between 0 and 24 hours. The inhibition of sortilin by $\operatorname{siSORT}$ resulted in a $61 \%$ reduction of cell migration in
PANC-1 $(P<0.001), 86 \%$ in MIA PaCa-2 $(P<0.001)$, and $69 \%$ in $\mathrm{PaCa}-44(P<0.001)$ compared with control (siCTRL) (Figure 5B). Treatment with AF38469 also impaired the migration capability at $78 \%, 76 \%$, and $79 \%$ in PANC-1, MIA PaCa-2, and $\mathrm{PaCa}-44$, respectively $(P<0.001)$ (Figure 5B). Overall, sortilin inhibition significantly reduced pancreatic cancer cell migration. In addition, invasion assays were performed. The crystal violet staining of invaded cancer cells showed a decreased proportion of invading cells in siSORT and AF38469 compared with controls (Figure 5C). There was a $66 \%$ reduction of cell invasion in PANC-1 $(P=0.0068), 61 \%$ in MIA PaCa$2(P<0.0001)$, and $57 \%$ in $\mathrm{PaCa}-44(P=0.0013)$ in siSORT. In AF38469-treated cells, there was a 63\%, 56\%, and $60 \%$ decrease in cell invasion (Figure 5C). These results, based on both RNA interference and pharmacologic inhibition, showed that sortilin is necessary to pancreatic cancer cell migration and invasion.

It should be noted that the effects of siSORT (Figures 4 and 5) were confirmed with a second siRNA sequence (Supplemental Figure S3).

\section{Sortilin Inhibition Attenuates FAK Signaling}

The impact of sortilin inhibition on the activation of a series of signaling proteins (FAK, GSK-3 $\beta$, Akt, Src, and Erk) in PANC-1, MIA PaCa-2, and PaCa-44 cells was then evaluated. Sortilin inhibition did not alter the phosphorylation of pAkt (Ser473), pSrc (Tyr416), pGSK-3 $\beta$ (Ser9), or pErk1/2 (Thr202/Tyr204) (Figure 6 and Supplemental Figure S4). In
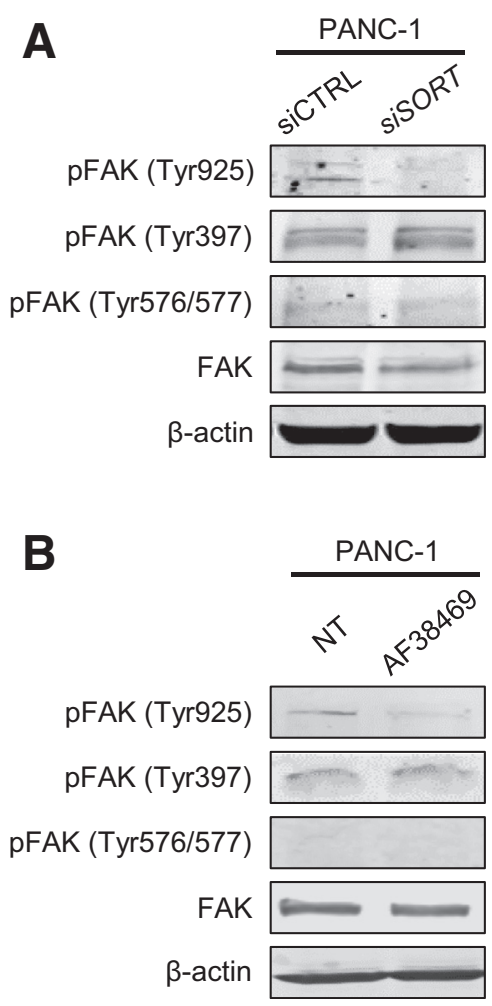
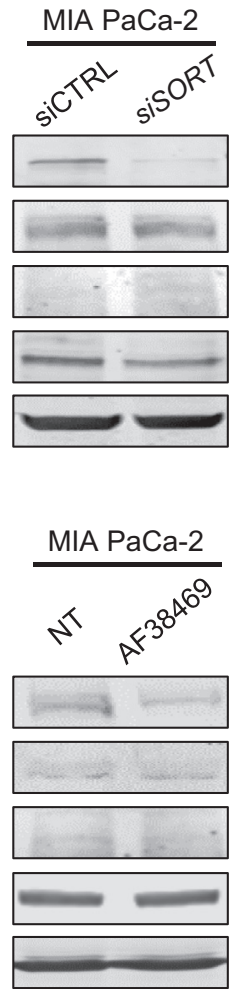
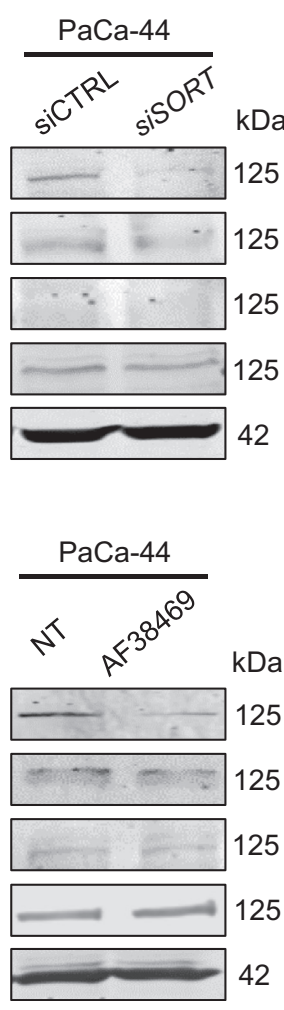

Figure 6 Impact of sortilin inhibition on phosphorylation of focal adhesion kinase (FAK). A: Phosphorylation of FAK (Tyr925), FAK (Tyr397), and FAK (Tyr576/577) in 72 hours' transfection with siCTRL versus siSORT is shown. Total FAK protein level is also shown. $\beta$-actin was used as loading control. The phosphorylation of residue Tyr925 of FAK is decreased in sortilin-inhibited samples compared with siCTRL. The phosphorylation of residues Tyr397 and Tyr576/577 of FAK are not affected by the inhibition of sortilin. B: Detection of phosphorylation of FAK (Tyr925), FAK (Tyr397), and FAK (Tyr576/577) via Western blot analysis after treatment with AF38469. Total FAK protein level is also shown. $\beta$-actin was used as loading control. The phosphorylation of residue Tyr925 of FAK decreases in sortilin-inhibited samples compared with no treatment (NT) control. 
contrast, phospho-FAK (Tyr925) was reduced in siSORT condition (Figure 6A). In contrast, the other phosphorylated forms of FAK (Tyr397 and Tyr576/577) were not affected by siSORT (Figure 6A). The pharmacologic inhibitor AF38469 was used to inhibit sortilin in PANC-1, MIA $\mathrm{PaCa}-2$, and PaCa-44. Phosphorylation of FAK was reduced at residue Tyr925 after treatment with AF38469 (Figure 6B), confirming the siRNA findings (Figure 6A). The phosphorylation of Src (Tyr416) was moderately reduced by the inhibition of sortilin in PANC-1 and $\mathrm{PaCa}-$ 44 cells, although not in MIA PaCa-2. Together, these data show that targeting sortilin reduces the activation of phospho-FAK (Tyr925).

\section{Discussion}

The current study is the first to report sortilin expression and function in human pancreatic cancer. The results highlight an increased sortilin protein level in pancreatic cancer cells compared with normal pancreatic epithelial cells. Furthermore, sortilin was found to contribute to pancreatic cancer invasion in vitro, through potentially maintaining an FAK signaling pathway. However, there was no clearly significant association between sortilin expression and pancreatic cancer aggressiveness, indicating that although sortilin contributes to pancreatic cancer cell invasion, it is not the only factor involved.

In terms of gene expression, sortilin mRNA abundance is not reportedly associated with pancreatic cancer or related clinicopathologic parameters. Data mining, using cBioportal and The Cancer Genome Atlas database for pancreatic cancer, indicated that SORTI is altered in 2\% of 295 pancreatic cancer samples, with only one case of amplification, three homozygous deletions, and two mutations. Initial studies in yeast comparing mRNA versus protein levels have suggested a correlation of $\sim 50 \%$ between mRNA and protein levels. ${ }^{27}$ In humans, transcriptomic and proteomic analyses have shown that only an estimated $30 \%$ to $60 \%$ of changes in protein levels can be explained by corresponding variations in mRNA. ${ }^{28}$ Translation efficiency is highly diverse, both quantitatively and qualitatively, and no linear relationship between mRNA abundance and individual protein synthesis rate can be assumed. ${ }^{29}$ In addition, a proteogenomic investigation in colorectal cancer showed that mRNA abundance does not reliably predict differences in protein abundance between tumors. ${ }^{30}$ This finding emphasizes the importance of analyzing protein levels because gene expression data may not necessarily reflect the abundance of the protein effectors in cancer.

High invasion is a hallmark of pancreatic cancer that is directly responsible for the high mortality rate of the disease. Locally advanced pancreatic cancer complicates surgical resection and predicts a poor prognosis. ${ }^{31,32}$ In breast cancer, sortilin was found to be related to tumor aggressiveness as well as cancer cell adhesion and invasion. ${ }^{17}$ The level of sortilin was also higher in non-small cell lung adenocarcinoma compared with small cell lung cancer. ${ }^{18}$ Sortilin has been reported in EGFR (epidermal growth factor receptor) mutant lung cancer, in which EGFR signaling is consistently stimulated, and sortilin limits cell viability by regulating EGFR internalization. ${ }^{33}$ Our analysis of cell signaling suggests that targeting sortilin, by using either siRNA or pharmacologic inhibition, decreases phosphorylation of FAK (Tyr925). Decreased phospho-FAK generally leads to less metastatic capability in cancers. ${ }^{34}$ Reports have shown that phosphorylation of FAK at the Tyr925 residue plays a critical role in the modulation of cell migration and adhesion through coordinating focal adhesion disassembly or modeling cell edge protrusion. ${ }^{35}$ The current study identified that sortilin depletion or pharmacologic inhibition diminished the activation of phospho-FAK925, and hence cell adhesion and invasion ability were reduced. In addition to acting as the neuronal membrane receptor, sortilin can be cleaved by the metalloproteinases ADAM10 and ADAM17 at a site close to the cellular membrane, resulting in the release of the soluble extracellular domain of sortilin. ${ }^{21,36}$ Therefore, we cannot exclude in the current study that the effect of sortilin inhibition on pancreatic cancer cell lines could involve, at least partly, inhibition of the soluble form of sortilin. AF38469 is a novel selective bioavailable pharmacologic inhibitor of sortilin that exhibits a specific interaction with sortilin, as shown in X-ray crystallography. ${ }^{37}$ Here, AF38469 inhibits pancreatic cancer cell adhesion and invasion, and also reduces the phosphorylation of FAK. The precise molecular involvement of sortilin in pancreatic cancer cell signaling and the potential for targeting it in therapy warrant further investigations.

Intriguingly, it was also found that sortilin levels were higher in female pancreatic cancer patients compared with male patients. It has been suggested that sortilin has a role in energy regulation and lipid homeostasis in female mice, not in male mice, and thus it may eventually be a sex-specific potential therapeutic target for obesity and cardiovascular disease. ${ }^{14}$ In clinical therapies for female patients with pancreatic cancer, the combination of gemcitabine with tamoxifen reportedly improves the efficacy of the chemotherapy. ${ }^{38}$ Our finding of higher sortilin expression in female patients suggests a possible regulation of sortilin gene expression by estrogen receptors, but further functional analyses are needed to confirm this hypothesis.

In conclusion, our study reveals sortilin as a potential therapeutic target in pancreatic cancer, and the clinical value of targeting sortilin should be further investigated. Interestingly, sortilin is also a nociceptor involved in the transmission of pain by sensory neurons, ${ }^{39}$ and AF38469 can impair neuropathic pain. ${ }^{40}$ Therefore, targeting sortilin in pancreatic cancer could also potentially address the issue of tumor-associated pain. Using a broader perspective, it should be emphasized that sortilin was originally identified and is predominantly expressed in neuronal cells. 
Neuroproteins are increasingly described in cancer, and neurosignaling participates in cancer progression. ${ }^{41}$ In pancreatic cancer, sensory and adrenergic neurosignaling stimulates cancer progression, ${ }^{42,43}$ whereas cholinergic neurosignaling is inhibitory. ${ }^{44}$ In this context, our study provides a further indication that neuroproteins such as sortilin are involved in pancreatic cancer and should be further considered as potential biomarkers and therapeutic targets.

\section{Acknowledgments}

We thank Mark Marsland and Kristen McEwan for excellent technical assistance.

\section{Supplemental Data}

Supplemental material for this article can be found at http://doi.org/10.1016/j.ajpath.2020.05.018.

\section{References}

1. Rawla P, Sunkara T, Gaduputi V: Epidemiology of pancreatic cancer: global trends, etiology and risk factors. World J Oncol 2019, 10: $10-27$

2. Davis JL, Pandalai PK, Ripley RT, Langan RC, Avital I: Expanding surgical treatment of pancreatic cancer: the role of regional chemotherapy. Pancreas 2012, 41:678-684

3. Manji GA, Olive KP, Saenger YM, Oberstein P: Current and emerging therapies in metastatic pancreatic cancer. Clin Cancer Res 2017, 23:1670-1678

4. Petersen CM, Nielsen MS, Nykjaer A, Jacobsen L, Tommerup N, Rasmussen HH, Roigaard H, Gliemann J, Madsen P, Moestrup SK: Molecular identification of a novel candidate sorting receptor purified from human brain by receptor-associated protein affinity chromatography. J Biol Chem 1997, 272:3599-3605

5. Vaegter CB, Jansen P, Fjorback AW, Glerup S, Skeldal S, Kjolby M, Richner M, Erdmann B, Nyengaard JR, Tessarollo L, Lewin GR, Willnow TE, Chao MV, Nykjaer A: Sortilin associates with Trk receptors to enhance anterograde transport and neurotrophin signaling. Nat Neurosci 2011, 14:54-61

6. Bradshaw RA, Pundavela J, Biarc J, Chalkley RJ, Burlingame AL, Hondermarck H: NGF and ProNGF: regulation of neuronal and neoplastic responses through receptor signaling. Adv Biol Regul 2015, 58:16-27

7. Pirault J, Polyzos KA, Petri MH, Ketelhuth DFJ, Bäck M, Hansson GK: The inflammatory cytokine interferon-gamma inhibits sortilin-1 expression in hepatocytes via the JAK/STAT pathway. Eur J Immunol 2017, 47:1918-1924

8. Wilson CM, Naves T, Vincent F, Melloni B, Bonnaud F, Lalloué F, Jauberteau MO: Sortilin mediates the release and transfer of exosomes in concert with two tyrosine kinase receptors. J Cell Sci 2014, 127:3983-3997

9. Reichardt LF: Neurotrophin-regulated signalling pathways. Philos Trans R Soc Lond B Biol Sci 2006, 361:1545-1564

10. Bogan JS, Kandror KV: Biogenesis and regulation of insulinresponsive vesicles containing GLUT4. Curr Opin Cell Biol 2010, 22:506-512

11. Ariga M, Nedachi T, Katagiri H, Kanzaki M: Functional role of sortilin in myogenesis and development of insulin-responsive glucose transport system in C2C12 myocytes. J Biol Chem 2008, 283: $10208-10220$

12. Chen C, Li J, Matye DJ, Wang Y, Li T: Hepatocyte sortilin 1 knockout and treatment with a sortilin 1 inhibitor reduced plasma cholesterol in Western diet-fed mice. J Lipid Res 2019, 60: 539-549

13. Blondeau N, Béraud-Dufour S, Lebrun P, Hivelin C, Coppola T: Sortilin in glucose homeostasis: from accessory protein to key player? Front Pharmacol 2018, 9:1561

14. Hagita S, Rogers MA, Pham T, Wen JR, Mlynarchik AK, Aikawa M, Aikawa E: Transcriptional control of intestinal cholesterol absorption, adipose energy expenditure and lipid handling by sortilin. Sci Rep 2018, 8:9006

15. Goettsch C, Hutcheson JD, Aikawa M, Iwata H, Pham T, Nykjaer A, Kjolby M, Rogers M, Michel T, Shibasaki M, Hagita S, Kramann R, Rader DJ, Libby P, Singh SA, Aikawa E: Sortilin mediates vascular calcification via its recruitment into extracellular vesicles. J Clin Invest 2016, 126:1323-1336

16. Kjolby M, Andersen OM, Breiderhoff T, Fjorback AW, Pedersen KM, Madsen P, Jansen P, Heeren J, Willnow TE, Nykjaer A: Sort1, encoded by the cardiovascular risk locus $1 \mathrm{p} 13.3$, is a regulator of hepatic lipoprotein export. Cell Metab 2010, 12:213-223

17. Roselli S, Pundavela J, Demont Y, Faulkner S, Keene S, Attia J, Jiang CC, Zhang XD, Walker MM, Hondermarck H: Sortilin is associated with breast cancer aggressiveness and contributes to tumor cell adhesion and invasion. Oncotarget 2015, 6:10473-10486

18. Gao F, Griffin N, Faulkner S, Rowe CW, Williams L, Roselli S, Thorne RF, Ferdoushi A, Jobling P, Walker MM, Hondermarck H: The neurotrophic tyrosine kinase receptor TrkA and its ligand NGF are increased in squamous cell carcinomas of the lung. Sci Rep 2018, 8:8135

19. Faulkner S, Jobling P, Rowe CW, Rodrigues Oliveira SM, Roselli S, Thorne RF, Oldmeadow C, Attia J, Jiang CC, Zhang XD, Walker MM, Hondermarck H: Neurotrophin receptors TrkA, p75 ${ }^{\mathrm{NTR}}$, and sortilin are increased and targetable in thyroid cancer. Am J Pathol 2018, 188:229-241

20. Yang W, Wu PF, Ma JX, Liao MJ, Wang XH, Xu LS, Xu MH, Yi L: Sortilin promotes glioblastoma invasion and mesenchymal transition through GSK-3beta/beta-catenin/twist pathway. Cell Death Dis 2019 , 10:208

21. Béraud-Dufour S, Devader C, Massa F, Roulot M, Coppola T, Mazella J: Focal adhesion kinase-dependent role of the soluble form of neurotensin receptor-3/sortilin in colorectal cancer cell dissociation. Int J Mol Sci 2016, 17

22. Kim JT, Napier DL, Weiss HL, Lee EY, Townsend CM Jr, Evers BM: Neurotensin receptor 3/sortilin contributes to tumorigenesis of neuroendocrine tumors through augmentation of cell adhesion and migration. Neoplasia 2018, 20:175-181

23. Dun MD, Chalkley RJ, Faulkner S, Keene S, Avery-Kiejda KA, Scott RJ, Falkenby LG, Cairns MJ, Larsen MR, Bradshaw RA, Hondermarck H: Proteotranscriptomic profiling of 231-BR breast cancer cells: identification of potential biomarkers and therapeutic targets for brain metastasis. Mol Cell Proteomics 2015, 14: 2316-2330

24. Pundavela J, Demont Y, Jobling P, Lincz LF, Roselli S, Thorne RF, Bond D, Bradshaw RA, Walker MM, Hondermarck H: ProNGF correlates with Gleason score and is a potential driver of nerve infiltration in prostate cancer. Am J Pathol 2014, 184:3156-3162

25. Nagtegaal ID, Odze RD, Klimstra D, Paradis V, Rugge M, Schirmacher P, Washington KM, Carneiro F, Cree IA, WHO Classification of Tumours Editorial Board: The 2019 WHO classification of tumours of the digestive system. Histopathology 2020, 76: $182-188$

26. Sidaway P: Pancreatic cancer: TCGA data reveal a highly heterogeneous disease. Nat Rev Clin Oncol 2017, 14:648

27. Vogel C, Marcotte EM: Insights into the regulation of protein abundance from proteomic and transcriptomic analyses. Nat Rev Genet 2012, 13:227-232 
28. Li JJ, Bickel PJ, Biggin MD: System wide analyses have underestimated protein abundances and the importance of transcription in mammals. PeerJ 2014, 2:e270

29. Maier T, Güell M, Serrano L: Correlation of mRNA and protein in complex biological samples. FEBS Lett 2009, 583:3966-3973

30. Zhang B, Wang J, Wang X, Zhu J, Liu Q, Shi Z, Chambers MC, Zimmerman LJ, Shaddox KF, Kim S, Davies SR, Wang S, Wang P, Kinsinger CR, Rivers RC, Rodriguez H, Townsend RR, Ellis MJ, Carr SA, Tabb DL, Coffey RJ, Slebos RJ, Liebler DC, NCI CPTAC: Proteogenomic characterization of human colon and rectal cancer. Nature 2014, 513:382-387

31. Kleeff J, Korc M, Apte M, La Vecchia C, Johnson CD, Biankin AV, Neale RE, Tempero M, Tuveson DA, Hruban RH, Neoptolemos JP: Pancreatic cancer. Nat Rev Dis Primers 2016, 2:16022

32. Liang C, Shi S, Meng Q, Liang D, Ji S, Zhang B, Qin Y, Xu J, Ni Q, Yu X: Complex roles of the stroma in the intrinsic resistance to gemcitabine in pancreatic cancer: where we are and where we are going. Exp Mol Med 2017, 49:e406

33. Al-Akhrass $H$, Naves $T$, Vincent F, Magnaudeix A, Durand $K$, Bertin F, Melloni B, Jauberteau MO, Lalloué F: Sortilin limits EGFR signaling by promoting its internalization in lung cancer. Nat Commun 2017, 8:1182

34. Sulzmaier FJ, Jean C, Schlaepfer DD: FAK in cancer: mechanistic findings and clinical applications. Nat Rev Cancer 2014, 14:598-610

35. Deramaudt TB, Dujardin D, Hamadi A, Noulet F, Kolli K, De Mey J, Takeda K, Rondé P: FAK phosphorylation at Tyr-925 regulates cross-talk between focal adhesion turnover and cell protrusion. Mol Biol Cell 2011, 22:964-975

36. Talbot H, Saada S, Naves T, Gallet PF, Fauchais AL, Jauberteau MO: Regulatory roles of sortilin and SorLA in immune-related processes. Front Pharmacol 2019, 9:1507

37. Schrøder TJ, Christensen S, Lindberg S, Langgard M, David L, Maltas PJ, Eskildsen J, Jacobsen J, Tagmose L, Simonsen KB, Biilmann Rønn LC, De Jong IE, Malik IJ, Karlsson JJ, Bundgaard C, Egebjerg J, Stavenhagen JB, Strandbygard D, Thirup S, Andersen JL, Uppalanchi S, Pervaram S, Kasturi SP, Eradi P, Sakumudi DR, Watson SP: The identification of AF38469: an orally bioavailable inhibitor of the VPS10P family sorting receptor sortilin. Bioorg Med Chem Lett 2014, 24:177-180

38. Tomao S, Romiti A, Massidda B, Ionta MT, Farris A, Zullo A, Brescia A, Santuari L, Frati L: A phase II study of gemcitabine and tamoxifen in advanced pancreatic cancer. Anticancer Res 2002, 22: $2361-2364$

39. Lewin GR, Nykjaer A: Pro-neurotrophins, sortilin, and nociception. Eur J Neurosci 2014, 39:363-374

40. Richner M, Pallesen LT, Ulrichsen M, Poulsen ET, Holm TH, Login H, Castonguay A, Lorenzo LE, Goncalves NP, Andersen OM, Lykke-Hartmann K, Enghild JJ, Rønn LCB, Malik IJ, De Koninck Y, Bjerrum OJ, Vaegter CB, Nykjaer A: Sortilin gates neurotensin and BDNF signaling to control peripheral neuropathic pain. Sci Adv 2019, 5:eaav9946

41. Faulkner S, Jobling P, March B, Jiang CC, Hondermarck H: Tumor neurobiology and the war of nerves in cancer. Cancer Discov 2019, 9: 702-710

42. Saloman JL, Albers KM, Li D, Hartman DJ, Crawford HC, Muha EA, Rhim AD, Davis BM: Ablation of sensory neurons in a genetic model of pancreatic ductal adenocarcinoma slows initiation and progression of cancer. Proc Natl Acad Sci U S A 2016, 113: 3078-3083

43. Renz BW, Takahashi R, Tanaka T, Macchini M, Hayakawa Y, Dantes Z, Maurer HC, Chen X, Jiang Z, Westphalen CB, Ilmer M, Valenti G, Mohanta SK, Habenicht AJR, Middelhoff M, Chu T, Nagar K, Tailor Y, Casadei R, Di Marco M, Kleespies A, Friedman RA, Remotti H, Reichert M, Worthley DL, Neumann J, Werner J, Iuga AC, Olive KP, Wang TC: Beta2 adrenergic-neurotrophin feedforward loop promotes pancreatic cancer. Cancer Cell 2018, 34:863-867

44. Renz BW, Tanaka T, Sunagawa M, Takahashi R, Jiang Z, Macchini M, Dantes Z, Valenti G, White RA, Middelhoff MA, Ilmer M, Oberstein PE, Angele MK, Deng H, Hayakawa Y, Westphalen CB, Werner J, Remotti H, Reichert M, Tailor YH, Nagar K, Friedman RA, Iuga AC, Olive KP, Wang TC: Cholinergic signaling via muscarinic receptors directly and indirectly suppresses pancreatic tumorigenesis and cancer stemness. Cancer Discov 2018, 8:1458-1473 